
cultures

Les cahiers de l'Acedle

14-1 | 2017

Notions en questions - Emergentisme

\title{
Emergentism: wide ranging theoretical framework or just one more meta-theory?
}

\section{Wander Lowie}

\section{(2) OpenEdition \\ Journals}

Édition électronique

URL : http://journals.openedition.org/rdlc/1140

DOI : $10.4000 /$ rdlc. 1140

ISSN : 1958-5772

Éditeur

ACEDLE

Référence électronique

Wander Lowie, " Emergentism: wide ranging theoretical framework or just one more meta-theory? », Recherches en didactique des langues et des cultures [En ligne], 14-1 | 2017, mis en ligne le 23 décembre 2016, consulté le 01 mai 2019. URL : http://journals.openedition.org/rdlc/1140 ; DOI : 10.4000/ rdlc. 1140

Ce document a été généré automatiquement le 1 mai 2019.

\section{cc) (†) $\Theta$}

Recherches en didactique des langues et des cultures is licensed under a Creative Commons AttributionNonCommercial-NoDerivatives 4.0 International License 


\title{
Emergentism: wide ranging theoretical framework or just one more meta-theory?
}

\author{
Wander Lowie
}

\section{Introduction}

1 The value of linguistic theories rests on the extent to which these theories can accurately describe and explain language use. Likewise, the value of a theory of language acquisition hinges on its power to describe and explain language acquisition, multilingual language use, and language attrition at all time scales, varying from milliseconds to the lifespan. There is a wide range of language theories, varying from the Monitor Theory and Processability Theory to Sociocultural theory and the Competition Model. Yet, there are essentially two families of theories that are largely incompatible: theories that view language as an inborn system that develops in a predetermined way (Universal Grammar or UG) and theories that view language as a system that emerges through perception and use of language (Emergentism), which is based on general cognitive abilities, and is not predetermined. In this short contribution I will discuss the essence and the added value of emergentist approaches to second language acquisition with a focus on complex dynamic systems theory, and I will address the questions of how emergentist approaches help us to understand how learner language develops and what implications emergentist approaches may have for language teaching.

2 Contrasting the two key theories of language, one of the fundamental distinctions is the question of whether language is a genetically determined, inborn system for which a specific language faculty must be assumed or an emergent system that makes use of general cognitive abilities of noticing and categorization. The central argument of the UG theory is that the input that learners are exposed to, including the lack of consistent negative evidence, provides insufficient information to acquire the complexity of the language system, an argument referred to as the "poverty of the stimulus » (Chomsky, 
1980). The argument is that if it can indeed be convincingly demonstrated that languages cannot be learned from input and interaction, it must be assumed that language is innate. Consequently, the discussion has focused on this point. While UG argumentation has based its evidence on logical argumentation and experiments to show that children use language in a way they cannot actively have « learned ", the Usage-Based or Emergentist approach has focused on demonstrating that language can perfectly well be learned from input and communicative interaction (Tomasello, 2003). A rather compelling line of research is found in connectionist approaches to language learning that have extensively investigated possibilities of statistical learning. Computer algorithms using Simple Recurrent Networks have shown that conclusions about language constructions can be drawn accurately and convincingly based on the input of natural language alone (Lewis \& Elman, 2002). This implies that the input is not as impoverished as might be assumed. In line with these findings, the emergentist theory of language acquisition emphasizes the richness of interactions and argues that language emerges " from interactions at all levels from brain to society " (Ellis, $1998: 631$ ), and that "simple learning mechanisms suffice to drive the emergence of complex language representations" (id, 631). Even though no conclusion about this argument has been reached that is acceptable to all stakeholders, there is increasing evidence against the poverty of the stimulus argument and the nativist approach to language is losing ground.

\section{A dynamic framework of emerging language}

3 A relatively recent contribution to the emergentist and usage-based framework is the Complex Dynamic Systems Theory (CDST) of language development. CDST hinges on the concept of dynamic development as it emerges over time. In this perspective, each subsequent step in time in the developing language system depends on the previous state of that system in dynamic interaction with the state of a large number of relevant systems, or, as phrased by Thelen (2005: 271) : «Every act in every moment is the emergent product of context and history, and no component has causal priority ». Due to the iterative and strongly interactive nature of language development, the highly individual process of development cannot be predetermined and the developmental trajectory is variable and nonlinear (De Bot, Lowie, \& Verspoor, 2007). For a number of these characteristics, I will elaborate on the way in which the emergent dynamic systems approach can help us understand second language learning.

4 Emergent complex dynamic systems are characterized by an infinite number of subsystems that interact over time and that mutually depend on the availability of resources. This implies that subsystems that are most relevant for language learning, like phonology, syntax and lexicon are closely interconnected and that their mutual influence may change from moment to moment. For instance, at early stages of language acquisition we may observe that syntax is heavily dependent on lexicon, as complex sentences can only be made when a critical number of lexical items has been acquired. At later stages of acquisition, lexical development may be dependent on the acquisition of syntactic structures. Similar assumptions can be formulated about the relationship between lexical and phonological knowledge. And since there is no fundamental limit to the factors that can potentially affect and interact with language development, embodied roles and communicative structure can also interact with the emerging language system (MacWhinney \& O'Grady, 2015). This characteristic of language as an emerging dynamic 
system makes a strong case for the observation that language and gesture are strongly interrelated and that body language comprises an inseparable aspect of communicative interaction (Adams, 2010 ; Iverson \& Goldin-Meadow, 2005). The dynamic interaction of subsystems is also a powerful explanation of the observation that the knowledge of different languages in the multilingual speaker are interrelated in a complex way. Evidence of the interlingual interconnectedness is found in the literature on codeswitching and code mixing, which shows that a bilingual is not «two monolinguals in one person» (Grosjean, 1989). Instead, the different languages in a multilingual language user are strongly integrated. Consequently, the resulting comprehensive and complex picture of language development is that of a process embedded in the context of language use, and integrated in cognition, the body and the world.

The observation that language learning is a complex process of interacting subsystems that changes over time corroborates its highly individual nature. Each next step in time in the complex system is based on the state of the system at the previous moment in time. Within the individual, the dynamic interaction of subsystems will consequently change from moment to moment, in which each subsystem may change at a different time scale. For instance, someone's language learning aptitude may change slowly, while someone's motivation may change rapidly depending on the learning context including distraction and the need to communicate. Due to the strongly individual nature of these interactions, it is difficult or even impossible to generalize about changes in the time dimension for groups of learners. This is clearly illustrated by Molenaar \& Campbell (2009), who show that generalizations about interactions of variables for groups of people can only be made when they are based on observations at one moment in time. For changing interactions of variables over time, only case studies of individuals can logically be applied. This is why emergentist research into dynamic development necessarily makes use of individual case studies (see De Bot et al., 2007). Consequently, the individual nature of second language development also has important consequences for language teaching, as we will see later in this contribution.

Due to the complex interaction of subsystems, another characteristic of language as an emerging dynamic system is that the complex interaction of subsystems over time leads to a high degree of variability in language use and language acquisition. Variability in an emergentist CDST view is seen as a necessary characteristic of learning and is the result of two essential aspects of language development. First, variability is the result of the learner's adaptation to the environment and the learner's tendency to try out new structures. The learner experiments with new forms, and will make corrections based on observations from the environment. The amount of variability typically coincides with changes in development. An increase in the amount of variability is commonly followed by a developmental jump (Spoelman \& Verspoor, 2010). The analysis of intra-learner variability is illustrated in Figure 1 below from van Dijk \& van Geert (2002). This figure is a min-max graph of the use of special prepositions by a child in the acquisition of the mother tongue. The figure illustrates how the amount of variability strongly increases between November 1998 and January 1999. This strong increase in variability coincides with a sharp increase in the average number of spatial prepositions used by the child. Clearly, the learner needs to vary with forms to gradually sort out the most communicative and effective form. And since the learner will have limited resources like attention and focus, the strong development of one subsystem is likely to affect the development of other subsystems, which also manifests as variability. Conversely, no 
change is likely to occur when there is no variability, as is found in what is commonly referred to as fossilization. In those cases, some variability will always occur in some of the subsystems associated with language development, the amount of variability may not be sufficient to lead to developmental change. Due to the observation that variability is a necessary condition for change to take place, variability has been labelled as the "motor of change » (Lowie \& Verspoor, 2015).

Figure - Illustration of the relation between intra-learner variability and development in learning. This figure shows the number of spatial prepositions recorded in the acquisition of the first language of one since participant (van Dijk \& van Geert, 2002).

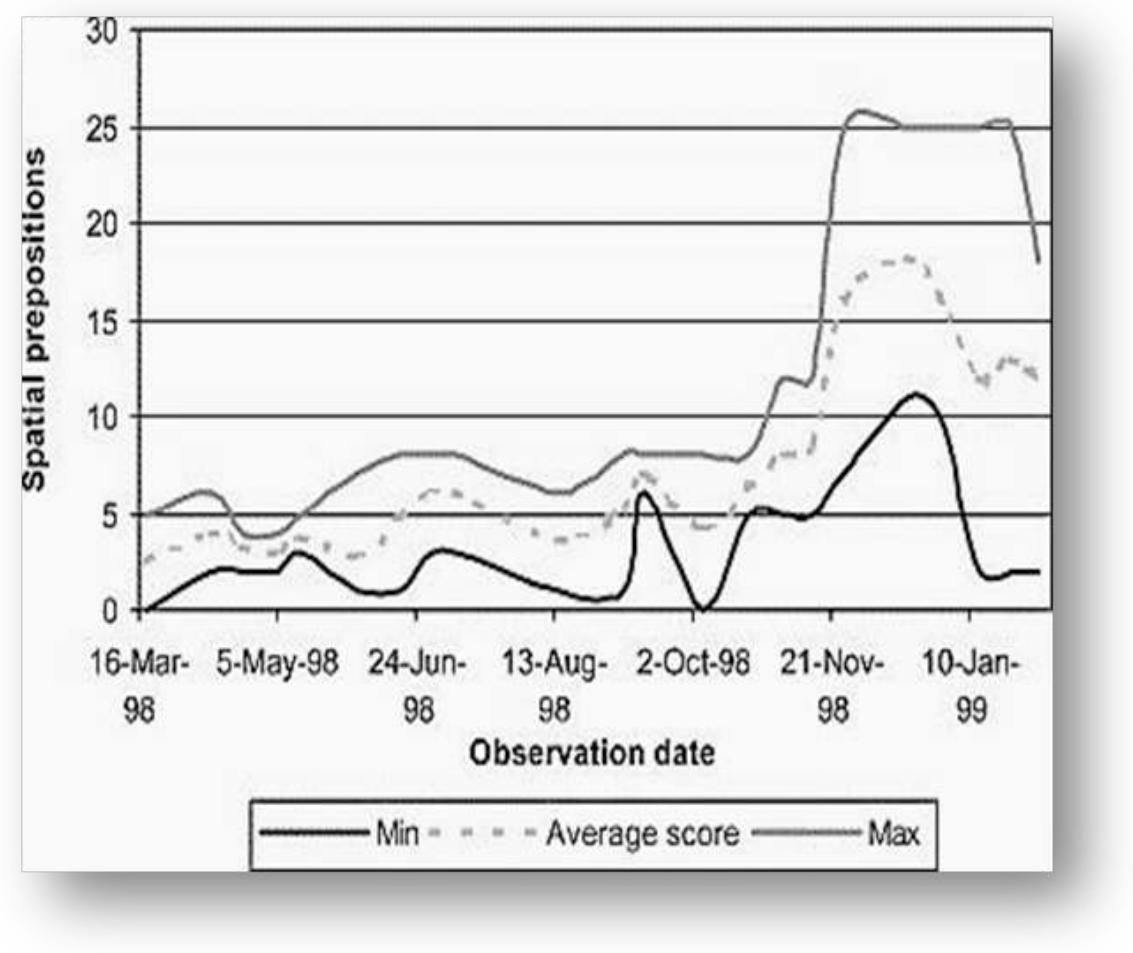

7 Second, variability is the result of the self-organizing principle that is characteristic of any dynamic system due to the interaction of subsystems. Learning is a dynamic process of adaptation and self-organization (Kelso, 1995). The combination of changing and interacting subsystems will lead to the emergence of attractor states that the system tends to develop towards. In typical self-organization in second language development, attractors are shaped by the combination of L1 and L2 subsystems, in which L1 related factors are often deeply ingrained and lead to deep L1-related attractors. A system that is optimally able to respond to changes in the environment and is fully flexible will therefore tend to move away from attractors (Lowie, Plat, \& Bot, 2014). From an emergentist, CDST perspective, variability must not be seen as an unwanted signal of failure to learn, but must be seen as a necessary and even crucial characteristic of learning. These observations, again, may have important implications for language teaching.

In sum, language acquisition from an emergent perspective is defined as a highly individual process in which numerous subsystems continuously interact in shaping development. The interactions materialize into a degree of intra-individual variability 
that is representative for the self-organizing process. Much variation signals that much learning is going on, while limited variation shows a relative attractor state of the system.

\section{Implications for research}

9 The dynamic characteristics of emerging language development have important implications for both research and teaching. One of the most important implications for research is that, since we can only answer the questions our method allows us, a clear division will have to be made between product-oriented questions and process-oriented questions. For questions about the relationships and interactions of variables affecting the product of learning as measured at one point in time, we can use studies that focus on groups of learners to make generalizations about trends observed. For process-based questions, however, we should rely on studies that follow the development of individuals over time, preferably closely following the development in dense, microgenetic measurements (Siegler \& Crowley, 1991). The reason for this is that human development in the time dimension is an iterative process in the individual history of all subsystems that determines the complex state of the system. Language development is not predetermined, but emerges from the complex history of all affecting factors, which include communication and input. Consequently, language development is essentially non-linear and difficult to predict. For very similar learners that learn the language in strongly comparable conditions, similarities between learners may of course occur. But microgenetic dynamic studies have shown that even identical twins that were exposed to identical input and used the language in highly similar ways, both in the same school and out of school, show very different patterns of second language development (Lowie, van Dijk, Chan, \& Verspoor, forthcoming). Therefore, instead of means analyses of groups of learners at two or three points in time, it is advisable to closely follow the development of individuals and use CDST methods, like variability analysis and language modelling to investigate how different subsystems influence one another as they develop over time (Verspoor, De Bot, \& Lowie, 2011). In other words, we should carefully reconsider the nature of the research question we want to investigate in second language acquisition and adjust our method accordingly.

A final remark with regard to research is that even though there may be relatively little variability at certain moments, there will always be some subsystems that change, regardless of the learner's level of proficiency. From an emergentist CDST point of departure, there is no final state of learning. Unlike the assumptions of Universal Grammar, in the emergentist view native speakers also differ in their language knowledge, language proficiency and the variability of their language use, and will be never reach a final state beyond further development. Consequently, the construct of " native speaker » should be treated with care and should be carefully used as framework of reference for second language learners or as baseline for comparison of developmental stages.

\section{Implications for second language teaching}

11 For many language teachers the growing evidence for language as an individually determined emergent and dynamic system is not good news. Traditionally, a primary role of language teachers is to provide explanations of grammar rules, vocabulary items, and 
pronunciation. However, when language is not a predetermined system but emerges from exposure and use, explanations about grammar may not be the optimal learning strategy. Especially for groups of learners this is problematic, as each individual may require different information, feedback and coaching at different moments in time. Individual coaching on grammar issues may be useful, but it will be hard to determine what input, practice and information the individual learner benefits from. Languages, we can conclude can be learned, but cannot be taught. The only thing a teacher can do is to provide optimal conditions for learning to take place. The optimal conditions are individually determined and may vary greatly over time. This may seem to be a very bleak perspective for language teaching. However, when we understand how language learning develops, our teaching may clearly benefit from that. The emergentist perspective certainly helps us to understand that learner development can be taken into account in second language education.

Probably the most important implication is the individual nature of second language development. When we acknowledge the individual state of the system and all its relevant subsystems, teaching strategies can be adjusted by making it more personally adaptive. The use of computer assisted language learning has been shown to create very useful tools for personalized learning through interactive communication (Jager, 2004). In general, a constructivist approach to learning as advocated by Piaget is logically more compatible with the emergent view than purely behaviourist methods. An emergentist addition to constructivist thinking could be the consideration that learning and use cannot be separated. Using language is an indispensable component of learning, and thus language learning cannot be separated from using language either productively or receptively.

Variability is another important lead to learning. In spite of the teacher's impatience and frustration that a learner still has not learned the correct forms even after many exercises and explanations, variability is a necessary condition for learning. Variability should therefore be acknowledged, aroused and enthused. The fossilized learner may pose a more obvious challenge for the teacher or language coach. The observed fossilization is the likely result of an attractor state. The comforting thought in this respect may be that with enough energy even deep attractor states can be routed. Getting the learner out of the attractor may require a strong perturbation that leads reorganization of one or more subsystems and that may result in increased variability to signal learning. The most appropriate perturbation can be any form of input, use, or instruction, but is again individually determined.

Variability also has important consequences for testing and assessment. Measuring at one point in time may not be representative of what the learner can optimally do in the language, especially when the focus of the assessment is on only one aspect of language use. A representative analysis of language development can only be based on a multidimensional assessment at different moments in time. Interestingly, the CANDO approach to language assessment as advocated by the Common European Framework of Reference (Council of Europe. European Centre for Modern Languages (ECML) (Graz, 2011), combined with language portfolios, is a compatible assessment that stimulates the learner to be in control of their own development (Lowie, 2013). 


\section{Conclusion}

15 In this short elaboration on the benefits of an emergentist view of second language acquisition, I hope to have convinced the reader that the emergentist perspective is not simply another meta-theory to reflect on language learning. The emergentist perspective, especially in combination with the complex dynamic systems theory of language development provides a wide-ranging theoretical framework that can help us understand the complex nature of second language development. The wide-ranging perspective shows us that language learning is not an isolated property but an integrated aspect of cognition. As part of cognition, language learning « is an event in time, the emergent product of many heterogeneous systems bound to each other and to the world in real time. Developmental change must reside in the real time changes (...) that emerge in this real time activity " (Smith, 2005 : 296). The emergentist perspective has important repercussions for both research into language development and for language instruction. This implies that we may have to abandon ideas about language acquisition that are firmly accepted by some of the stakeholders, and that we have to embrace the individual and variable nature of second language development.

\section{BIBLIOGRAPHIE}

Adams, F. (2010). « "Embodied cognition ». Phenomenology and the Cognitive Sciences, 9 (4).

pp. 619-628.

Chomsky, N. (1980). Rules and representations. New York : Columbia University Press.

Council of Europe. European Centre for Modern Languages (2011). Relating language examinations to the common European framework of reference for languages: Learning, teaching, assessment. Strasbourg : Council of Europe.

De Bot, K., Lowie, W., \& Verspoor, M. (2007). « A dynamic systems theory approach to second language acquisition ». Bilingualism, 10(1). pp. 7-21.

Ellis, N. (1998). « Emergentism, connectionism and language learning ». Language Learning, 48(4). pp. 631-664.

Grosjean, F. (1989). « Neurolinguists, beware! The bilingual is not two monolinguals in one perso ». Brain and Language, 36(1). pp. 3-15.

Iverson, J. M., \& Goldin-Meadow, S. (2005). « Gesture paves the way for language development ». Psychological Science, 16(5). pp. 367-371.

Jager, S. (2004). « Learning management systems for language learning ». In A. Chambers, J. E. Conacher \& J. Littlemore (Eds.), ICT and language learning : Integrating pedagogy and practice (pp. 33-48). Birmingham : University of Birmingham Press.

Kelso, J. A. S. (1995). Dynamic patterns : The self-organization of brain and behavior. Cambridge, MA etc. : The MIT Press. 
Lewis, J. D., \& Elman, J. L. (2002). « Learnability and the statistical structure of language : Poverty of stimulus arguments revisited ». Proceedings of the 26th Annual Boston University Conference on Language Development, Vols 1 and 2. pp. 359-368.

Lowie, W. (2013). « The CEFR and the dynamics of second language learning : Trends and challenges » Language Learning in Higher Education, 2(1). pp. 17-34.

Lowie, W., Van Dijk, M., Chan, H. P., \& Verspoor, M. H. (forthcoming). »Finding the key to successful L2 learning in groups and individuals« . Journal of Language Teaching and Learning.

Lowie, W., Plat, R., \& Bot, K. d. (2014). « Pink noise in language production : A nonlinear approach to the multilingual lexicon ». Ecological Psychology, 26(3). pp. 216-228.

Lowie, W., \& Verspoor, M. (2015). Variability and variation in second language acquisition orders : A dynamic reevaluation. Language Learning, 65(1). pp. 63-88.

MacWhinney, B., \& O'Grady, W. (2015). The handbook of language emergence. Hoboken : WileyBlackwell.

Molenaar, P. C. M., \& Campbell, C. G. (2009). « The new person-specific paradigm in psychology ». Current Directions in Psychological Science, 18(2). pp. 112-117.

Siegler, R. S., \& Crowley, K. (1991). « The microgenetic method : A direct means for studying cognitive development ». American Psychologist, 46(6). pp. 606-620.

Smith, L. B. (2005). « Cognition as a dynamic system : Principles from embodiment ». Developmental Review, 25(3/4). pp. 278-298.

Spoelman, M., \& Verspoor, M. (2010). « Dynamic patterns in the development of accuracy and complexity : A longitudinal case study on the acquisition of Finnish ». Applied Linguistics, 31(4). pp. 532-553.

Tomasello, M. (2003). Constructing a language : A usage-based theory of language acquisition. Cambridge, MA [etc.] : Harvard University Press.

van Dijk, M., \& van Geert, P. (2002). « Focus on variability : New tools to study intra-individual variability in developmental data ». Infant Behavior and Development, 25(4). pp. 340-375.

Verspoor, M., De Bot, K., \& Lowie, W. (Eds.). (2011). A dynamic systems approach to second language development: Methods and techniques. Amsterdam, Philadelphia : John Benjamins.

\section{RÉSUMÉS}

Cet article esquisse l'idée selon laquelle le développement d'une langue seconde serait un processus émergent répondant aux caractéristiques d'un système complexe. L'acquisition langagière, dans une perspective émergentiste, est définie comme un processus majoritairement individuel dans lequel des sous-systèmes interagissent en redéfinissant perpétuellement le système lui-même. L'interaction de ces sous-systèmes provoque un certain degré de variabilité intra-individuelle qui est caractéristique du processus d'apprentissage langagier: plus de variabilité indique plus d'apprentissage. La principale implication, pour la recherche sur l'acquisition langagière, porte sur le fait que nous avons besoin de plus d'études de cas longitudinales qui nous permettraient de tracer l'évolution du développement individuel au cours du temps. La principale implication pour l'enseignement est que nous devrions reconnaitre la variabilité langagière de chaque individu et que l'enseignement des langues devrait prendra la forme d'un « coaching » (tutorat). Une autre implication serait que l'usage d'une langue, comme un moyen actif de communication, est une condition indispensable à l'apprentissage. La 
perspective émergentiste offre un cadrage théorique large qui peut nous permettre de comprendre la nature complexe du développement langagier.

This paper outlines second language development as an emergent and complex dynamic process. Language acquisition from an emergent perspective is defined as a highly individual process in which subsystems continuously interact in shaping the ever-changing system. The interacting subsystems result in a degree of intra-individual variability that is characteristic for the process of language learning : more variability indicates more learning. The most important implication for research into language acquisition is that we need more longitudinal case studies that allow us to track individual development as it evolves over time. The most important implication for teaching is that we should acknowledge the variability in a learner's language and that language teaching should ideally take the form of individual coaching. Another implication is that using language as an active means of communication is an indispensable component of language learning. The emergentist perspective provides a wide-ranging theoretical framework that can help us understand the complex nature of second language development.

\section{INDEX}

Mots-clés : émergentisme, théorie des systèmes dynamiques, acquisition d'une langue seconde, variabilité, développement langagier

Keywords : emergentism, complex dynamic systems theory, second language acquisition, variability, language development

\section{AUTEUR}

\section{WANDER LOWIE}

Université de Groningen

Wander Lowie est docteur en linguistique à l'université de Groningen. Il est directeur du département de Linguistique Appliquée et membre du comité de direction du Centre du langage et de la cognition à l'université de Groningen. Il est éditeur associé de la revue The Modern Language Journal. Actuellement, ses recherches portent principalement sur les applications de la théorie des systèmes dynamiques au développement d'une langue seconde (enseignementapprentissage). Il a notamment publié deux ouvrages de référence dans le domaine : Essential Statistics for Applied Linguistics et A dynamic Approach to Second Language: Methods and Techniques. Avec Kees de Bot et Marjolijn Verspoor, il a co-rédigé une réflexion approfondie sur cette thématique : Second Language Acquisition : an Advanced Resource Book.

Courriel : w.m.lowie@rug.nl

Toile : http://www.rug.nl/staff/w.m.lowie/ 